\title{
Aditivos alimentares na dieta de bovinos confinados
}

\author{
[Feed additives in feedlot diets] \\ R.S. Barducci ${ }^{1}$, L.M. Sarti ${ }^{1}$, D.D. Millen ${ }^{2}$, R.D.L. Pacheco ${ }^{1}$, S.R. Baldin ${ }^{1}$, \\ F.S. Parra ${ }^{1}$, T.C. Putarov ${ }^{1}$, C.L. Martins ${ }^{1}$, M.D.B. Arrigoni ${ }^{1}$ \\ ${ }^{1}$ Universidade Estadual Paulista - Botucatu, SP \\ ${ }^{2}$ Faculdade de Zootecnia - Universidade Estadual Paulista - Dracena, SP
}

\section{RESUMO}

O objetivo do presente trabalho foi avaliar o efeito da inclusão do preparado de anticorpos policlonais (PAP) e/ou da monensina sódica (MON) sobre o desempenho, as características da carcaça, o perfil de ácidos graxos da carcaça (PAG) e a concentração de lipoproteínas sanguíneas (CLS) de bovinos confinados. O delineamento experimental foi inteiramente ao acaso, em arranjo fatorial $2 \times 2$, com medidas repetidas no tempo, sendo os fatores a inclusão ou não de MON e PAP avaliados em dois períodos, em que 72 bovinos machos da raça Brangus, não castrados, foram alocados em 24 baias (três animais/baia), totalizando seis repetições por tratamento. Não foi observado efeito $(\mathrm{P}>0,05)$ da inclusão do PAP para nenhuma das varáveis de desempenho e características de carcaça. Contudo, foi observado efeito $(\mathrm{P}<0,05)$ da inclusão de MON, em que animais que receberam MON apresentaram maiores ganho de peso diário (1,666 vs. 1,552), ganho de peso total $(179,95$ vs. $167,68)$, peso vivo final $(474,86 v s$. 459,61$)$, peso de carcaça quente $(248,46$ vs. 240,20$)$, melhor conversão alimentar $(5,57$ vs. 5,79) e reduzido custo para ganhar um quilo de peso vivo $(3,06$ vs. 3,18). Ainda não foi observado efeito principal $(\mathrm{P}>0,05)$ dos aditivos para o PAG e a CLS. Assim, a inclusão do PAP não foi boa alternativa à substituição da MON. Por outro lado, a inclusão do PAP não afetou negativamente os itens estudados.

Palavras-chave: confinamento, imunização passiva, ionóforo

\begin{abstract}
This study was designed to test the effects of polyclonal antibody preparation (PAP) against several rumen bacteria and/or monensin (MON) on feedlot performance, carcass characteristics, fatty acid profile and blood lipoprotein concentrations in yearling bulls. Seventy-two Brangus yearling bulls were distributed in a completely randomized design with $2 \times 2$ factorial arrangements of treatments with six replications; factors were the inclusion or not of PAP or MON, measured over two phases. No significant (P>0.05) PAP main effects were observed for any of the feedlot performance and carcass trait variables. However, significant $(P>0.05)$ MON main effects were observed, where animals receiving MON had higher $(P<0.05)$ average daily gain (1.666 vs. 1.552), total weight gain (179.95 vs. 167.68), final body weight (474.86 vs. 459.61), hot carcass weight (248.46 vs. 240.20), better feed: gain ratio (5.57 vs. 5.79) and better cost to gain one kilo of body weight (3.06 vs. 3.18). No significant $(P>0.05)$ main effects due to feed additives were observed for carcass fatty acid profile and blood lipoprotein concentrations. Therefore, the inclusion of PAP was not a good alternative to replace MON. On the other hand, feeding PAP did not negatively impact the items studied.
\end{abstract}

Keywords: Feedlot, passive immunization, ionophore

\section{INTRODUÇÃO}

Millen et al. (2009), com o objetivo de traçar o perfil dos confinamentos brasileiros, realizaram levantamento com 31 nutricionistas responsáveis pelo atendimento de aproximadamente 3,2 milhões de cabeças de animais confinados, e relataram que a inclusão média de ingredientes volumosos nas dietas foi de $28,8 \%$ com base na matéria seca (MS), sendo que $77,4 \%$ dos nutricionistas utilizavam entre 56 e $80 \%$ de concentrado (base na MS) e $100 \%$ dos clientes destes utilizavam ionóforos como principal aditivo alimentar.

Recebido em 4 de março de 2012

Aceito em 6 de março de 2013

E-mail: robsonbarducci@yahoo.com.br 
Em recente encontro da FAO/WHO Expert Committee on Food Additives (FAO, 2009), organizado em outubro de 2008, foram fixados limites máximos de utilização de aditivos (inclusive ionóforos) para a alimentação animal, porém essas disposições deverão ser revistas futuramente, levando-se em conta os novos conhecimentos científicos. Particularmente na União Europeia, entretanto, desde 2006 é proibido o uso de antibióticos ionóforos como promotores de crescimento.

Uma alternativa aos ionóforos que surge é a utilização do conceito de imunização passiva como nova ferramenta para manipular a fermentação ruminal, por meio de anticorpos policlonais produzidos contra bactérias ruminais específicas. O conceito do mecanismo de imunização como ferramenta para atingir maior eficiência na fermentação ruminal e, assim, melhorar o desempenho animal é relativamente recente (Sarti et al., 2009; Marino et al., 2011).

Portanto, o objetivo deste trabalho foi avaliar os efeitos da adição de anticorpos policlonais (contra as bactérias ruminais Streptococcus bovis, Fusobacterium necrophorum, Lactobacillus e endotoxina) e/ou da monensina sódica nas dietas sobre o desempenho, as características de carcaça, o perfil de ácidos graxos da carcaça e a concentração de lipoproteínas sanguíneas de bovinos Brangus confinados.

\section{MATERIAL E MÉTODOS}

O trabalho foi conduzido de acordo com as normas da Comissão de Ética em Experimentação Animal (CEEA), protocolo $\mathrm{n}^{\circ}$ $76 / 2008$.

O estudo foi conduzido na Faculdade de Medicina Veterinária e Zootecnia, Unesp - Univ. Estadual Paulista, campus de Botucatu, no confinamento experimental de bovinos de corte, onde foram alocados 72 animais machos não castrados da raça Brangus, desmamados aos nove meses de idade, com peso vivo médio inicial de $285,9 \pm 38,7 \mathrm{~kg}$ e distribuídos aleatoriamente em 24 baias (três animais/baia), sendo seis repetições por tratamento de acordo com o aditivo alimentar testado: controle (CONT - sem aditivo), anticorpos policlonais (PAP), monensina sódica (MON) e a mistura de anticorpos policlonais + monensina sódica (MIX).

Antes do início do experimento, todos os animais foram desverminados, pesados e submetidos a um período de adaptação (ADAP) utilizando-se protocolo de escadas, em que cada uma das três dietas utilizadas continham 57, 63 e $68 \%$ de concentrado, e foram fornecidas por sete dias, totalizando 21 dias de adaptação. Posteriormente, foram utilizadas duas dietas experimentais para as fases de crescimento (CRES) e terminação (TER), as quais continham 73 e $82 \%$ de concentrado e foram fornecidas por 66 e 42 dias, respectivamente. Desde o período de adaptação foram utilizadas as mesmas rações, as quais diferiam apenas no tocante aos aditivos alimentares fornecidos: controle (sem aditivo), MON (30mg/kg de MS), PAP (450mg/kg de MS) ou MIX (30mg de MON/kg de MS + 450mg de PAP/Kg de MS), sendo estes sólidos e na forma de pó e pré-misturados ao suplemento mineral. As rações oferecidas nesses períodos e na adaptação estão apresentadas na Tab. 1. As rações foram fornecidas ad libitum e duas vezes ao dia: às oito horas $(40 \%$ do total) e às $15 \mathrm{~h}$ (60\% do total), com água constante nos bebedouros automáticos. A ração foi submetida a ajustes de quantidade diariamente, com base na quantidade de sobra nos cochos de todas as baias antes da primeira refeição (oito horas), utilizando-se como critério sobras de $5 \%$.

Os animais foram pesados a cada 28 dias, sempre pela manhã (oito horas), após jejum de sólidos de 16 horas, para monitoramento do ganho de peso vivo médio diário (GPD). Também foi medida a ingestão diária de matéria seca (IMS) para cada baia por meio da pesagem do alimento fornecido diariamente. A determinação da MS da dieta total foi efetuada todos os dias para se obter a ingestão diária em quilos de MS. Posteriormente, foi feita a média de IMS por baia em quilos (IMSKG). Os dados de IMS também foram expressos em porcentagem do peso vivo (IMSPV). A conversão alimentar (CA) foi obtida pela divisão da IMSKG pelo GPD. 
Tabela 1. Ingredientes e composição química das dietas experimentais fornecidas durante o estudo

\begin{tabular}{lccccc} 
& \multicolumn{4}{c}{ Nível de concentrado } \\
\cline { 2 - 6 } Item & $57 \%$ & $63 \%$ & $68 \%$ & $73 \%$ & $82 \%$ \\
\hline & ADAP 1 & ADAP 2 & ADAP 3 & CRES & TER \\
Dias de alimentação & 7 & 7 & 7 & 66 & 42 \\
Ingredientes, \% da MS & & & & & \\
Feno de Coast Cross & 15,37 & 14,02 & 12,58 & 5,12 & 4,54 \\
Bagaço de Cana Cru & 26,94 & 23,48 & 20,71 & 21,77 & 13,62 \\
Silagem de grãos úmidos de milho & 23,14 & 27,74 & 32,21 & 36,20 & 47,52 \\
Polpa cítrica & 12,33 & 12,96 & 13,34 & 15,25 & 19,98 \\
Farelo de Soja & 20,70 & 20,27 & 19,63 & 20,14 & 12,85 \\
Suplemento mineral com 30\% ureia ${ }^{1}$ & 1,53 & 1,53 & 1,53 & 1,52 & 1,51 \\
Composição bromatológica & & & & & \\
MS (\% da matéria natural) & 72,0 & 71,0 & 69,0 & 70,0 & 68,0 \\
NDT & 71,0 & 73,0 & 75,0 & 76,0 & 80,0 \\
Elg,5, Mcal/kg de MS & 1,05 & 1,11 & 1,16 & 1,20 & 1,31 \\
Proteína bruta & 15,6 & 15,7 & 15,8 & 16,0 & 13,8 \\
Extrato Etéreo & 3,10 & 3,20 & 3,35 & 3,45 & 3,55 \\
FDN & 37,1 & 33,6 & 30,3 & 25,9 & 19,2 \\
Ca & 0,54 & 0,54 & 0,54 & 0,55 & 0,62 \\
P & 0,34 & 0,35 & 0,35 & 0,36 & 0,34 \\
\hline
\end{tabular}

${ }^{1}$ Suplemento continha 30\% de ureia, assim como Ca 9,1\%; P 4,0\%; Na 12,3\%; S 1,4\%; Mg 0,8\%; Zn 2592 ppm; Mn 1398 ppm; Cu 1032 ppm; I 45,0 ppm; Se 15,0 ppm; Co, 154 ppm e flúor 400 ppm. ${ }^{2}$ Nutrientes digestíveis totais. ${ }^{3}$ Energia líquida para ganho.

A cada 28 dias durante o período de confinamento, os animais foram monitorados por meio de ultrassonografia para o acompanhamento do crescimento dos tecidos adiposo e muscular, segundo metodologia proposta por Greiner et al. (2003), para verificar o desenvolvimento da espessura da gordura subcutânea (EGS), da área de olho de lombo (AOL) sobre o músculo Longissimus, entre as $12^{\mathrm{a}}$ e $13^{\mathrm{a}}$ costelas, bem como o desenvolvimento do tecido adiposo da garupa (P8) sobre o músculo Bíceps femoris. O ganho diário da AOL foi calculado subtraindo-se a AOL final da AOL inicial e dividindo-se pelo número de dias entre as medidas. Da mesma forma foram calculados o ganho diário da GSC e o ganho diário da P8.

As amostras de sangue foram colhidas por meio da punção da veia jugular externa, seguindo-se a metodologia proposta por Allain et al. (1974). Para determinação das concentrações de colesterol, triglicerídeos, lipoproteínas de baixa densidade (LDL) e lipoproteínas de alta densidade (HDL), foram utilizados kits enzimáticos comerciais. Logo após as análises, a concentração de lipoproteínas de muito baixa densidade (VLDL) no sangue foi calculada de forma indireta por diferença.

Os animais foram abatidos quando alcançaram o peso de abate de $480 \mathrm{~kg}$ e EGS mínima de quatro milímetros. Após o abate, as carcaças foram resfriadas por 24 horas, e, posteriormente, foram colhidas amostras de gordura subcutânea do músculo Longissimus (contrafilé) de 48 animais, sendo 12 animais por tratamento, acondicionadas em nitrogênio líquido para análise do perfil de ácidos graxos. A extração e a avaliação dos lipídeos totais foram realizadas de acordo com a metodologia modificada de Hara e Radin (1978), com uso de hexano/isopropanol 3:2 (v/v). Para a transesterificação e a metilação dos ácidos graxos, foi utilizada a metodologia descrita por Christie (1982), com modificações, utilizando-se solução metanólica de metóxido de sódio.

$O$ rendimento de carcaça $(\mathrm{RC})$ foi calculado da divisão do peso de carcaça quente (PCQ) pelo peso vivo final (PVF) do animal em jejum multiplicado por 100. A proporção de gordura visceral $(\mathrm{GV})$ foi estabelecida pela divisão do peso da gordura em quilos presente nos rins e pelve pelo PCQ. A análise econômica dos produtos testados neste estudo foi realizada com base no custo para ganho de um quilo de peso vivo (CKPV), calculado conforme a seguinte fórmula: (IMS x custo em $\mathrm{R} \$ / \mathrm{kg}$ de $\mathrm{MS}$ da dieta)/GPD.

$\mathrm{O}$ delineamento experimental foi inteiramente ao acaso, em arranjo fatorial $2 \times 2$, com medidas repetidas no tempo, sendo os fatores a inclusão 
ou não de MON e a inclusão ou não de PAP, avaliados em dois períodos, CRES e TER, totalizando 24 baias no experimento, com seis repetições (baias) por tratamento, sendo: T1 - CONT; T2 - PAP; T3 - MON; T4 - PAP + MON (MIX). Para a concentração das lipoproteínas do sangue foi adicionado mais um período de avaliação: ADAP.

Os resultados dos efeitos principais dos aditivos (PAP ou MON) foram apresentados e comparados da seguinte forma: tratamentos que não continham MON vs. tratamentos que continham MON e tratamentos que não continham PAP vs. tratamentos que continham PAP. Nas análises estatísticas, toda vez que ocorreu interação entre aditivos, os valores foram desmembrados entre os tratamentos: CONT, PAP, MON e MIX. As baias foram consideradas as unidades experimentais, e os animais unidades de observação. Os dados foram pelo PROC MIXED do SAS (Statistical..., 2003) por análise de variância. Resultados foram considerados significantes a $\mathrm{P}<0,05$.

\section{RESULTADOS}

Não foi observado $(\mathrm{P}>0,05)$ efeito da inclusão do PAP sobre nenhuma das variáveis de desempenho estudadas. No entanto, a inclusão de MON levou $(\mathrm{P}<0,05)$ a maiores GPD, ganho de peso total (GP), PVF, melhor CA e reduzido CKPV (Tab. 2).

Com respeito aos períodos analisados, foi observado efeito $(\mathrm{P}<0,05)$ para todas as variáveis de desempenho estudadas (Tab. 2).

Tabela 2. Desempenho de bovinos Brangus jovens confinados com anticorpos policlonais (PAP) e/ou monensina sódica (MON)

\begin{tabular}{|c|c|c|c|c|c|c|c|c|c|c|}
\hline \multirow{2}{*}{ Item $^{c}$} & \multicolumn{2}{|c|}{$\mathrm{PAP}^{\mathrm{d}}$} & \multicolumn{2}{|c|}{$\mathrm{MON}^{\mathrm{e}}$} & \multicolumn{2}{|c|}{ Período (PER) } & \multicolumn{3}{|c|}{ Probabilidade } & \multirow{2}{*}{$\mathrm{EPM}^{\mathrm{f}}$} \\
\hline & - & + & - & + & CRES & TER & PAP & MON & PER & \\
\hline PV inicial, $\mathrm{kg}$ & 294,29 & 292,53 & 291,92 & 294,90 & $293,41 b$ & $423,87 a$ & 0,516 & 0,275 & $<, 0001$ & 2,435 \\
\hline PV final, $\mathrm{kg}$ & 466,28 & 468,19 & $459,61 \mathrm{a}$ & $474,86 \mathrm{~b}$ & $423,87 b$ & $467,24 \mathrm{a}$ & 0,778 & 0,034 & $<, 0001$ & 4,217 \\
\hline GPD, kg & 1,592 & 1,626 & $1,552 \mathrm{a}$ & $1,666 b$ & $1,979 a$ & $1,032 b$ & 0,558 & 0,041 & $<, 0001$ & 0,038 \\
\hline $\mathrm{GP}, \mathrm{kg}$ & 171,98 & 175,66 & $167,69 \mathrm{a}$ & $179,95 b$ & $130,63 \mathrm{a}$ & $43,36 b$ & 0,558 & 0,041 & $<, 0001$ & 2,186 \\
\hline IMS, $\mathrm{kg}$ & 9,08 & 9,16 & 8,96 & 9,28 & $9,03 b$ & $9,26 a$ & 0,703 & 0,162 & 0,0132 & 0,163 \\
\hline IMS, $\%$ do PV & 2,38 & 2,41 & 2,38 & 2,41 & $2,52 \mathrm{a}$ & $2,07 b$ & 0,561 & 0,446 & $<, 0001$ & 0,026 \\
\hline $\mathrm{CA}, \mathrm{kg} / \mathrm{kg}$ & 5,73 & 5,64 & $5,79 \mathrm{a}$ & $5,57 \mathrm{~b}$ & $4,58 b$ & $9,05^{\mathrm{a}}$ & 0,467 & 0,046 & $<, 0001$ & 0,125 \\
\hline $\mathrm{CKPV}, \mathrm{R} \$ / \mathrm{kg}$ & 3,14 & 3,09 & $3,18 \mathrm{a}$ & $3,06 \mathrm{~b}$ & $2,44 b$ & $5,11 \mathrm{a}$ & 0,461 & 0,044 & $<, 0001$ & 0,070 \\
\hline
\end{tabular}

${ }^{\mathrm{ab}} \mathrm{Na}$ mesma linha, médias com letras distintas diferem. ${ }^{\mathrm{c}} \mathrm{PV}=$ peso vivo; GPD = ganho de peso diário; GP = ganho de peso total; IMS = ingestão de matéria seca; $\mathrm{CA}=$ conversão alimentar; CKPV = custo para ganhar um quilo de PV. ${ }^{\mathrm{d}} \mathrm{PAP}(-)=$ Controle e MON; PAP $(+)=$ PAP e MIX. ${ }^{\mathrm{e}} \mathrm{MON}(-)=$ Controle e PAP; MON $(+)=$ MON e MIX. ${ }^{\mathrm{f}}$ Erropadrão da média.

Não foi observado $(\mathrm{P}>0,05)$ efeito da inclusão do PAP sobre nenhuma das variáveis de características de carcaça estudadas. No entanto, a inclusão de MON levou $(\mathrm{P}<0,05)$ à maior PCQ (Tab. 3).

Com respeito aos períodos analisados, foram observados efeitos $(\mathrm{P}<0,05)$ para as variáveis de ultrassonografia AOL inicial, AOL final, GSC inicial, GSC final, P8 inicial e P8 final, em que animais apresentaram menores valores no período de CRES em relação à fase de TER (Tab. 3).

Foi encontrada interação $(\mathrm{P}<0,05)$ entre os aditivos alimentares (Tab. 4) para as variáveis do ácido linoleico (C18:2) (Fig. 1), AGPI (Fig. 2), AGPI/AGS (Fig. 3) AGPI/AGMI (Fig. 4). Devido à interação entre aditivos alimentares, os valores foram desmembrados entre os tratamentos (CONT, PAP, MON e MIX). Entretanto, não foi observado efeito $(\mathrm{P}>0,05)$ dos valores das médias entre os tratamentos testados nas variáveis do ácido linoleico (Fig. 1), AGPI/AGS (Fig. 3), AGPI/AGMI (Fig. 4). Contudo, para a variável AGPI, os animais do tratamento MON apresentaram um menor valor $(\mathrm{P}<0,05)$ em relação aos animais do tratamento MIX (Fig. 2). Os demais tratamentos, PAP e CONT, foram semelhantes aos outros dois, não sendo observado efeito significativo $(\mathrm{P}>0,05)$.

Também não foi observado efeito $(\mathrm{P}>0,05)$ principal dos aditivos alimentares (PAP ou MON) para as variáveis de ácidos graxos estudados (Tab. 4). 
Aditivos alimentares...

Tabela 3. Características de carcaça em bovinos Brangus jovens confinados com anticorpos policlonais (PAP) e/ou monensina sódica (MON)

\begin{tabular}{|c|c|c|c|c|c|c|c|c|c|c|}
\hline \multirow{2}{*}{ Item $^{c}$} & \multicolumn{2}{|c|}{ PAP $^{d}$} & \multicolumn{2}{|c|}{$\mathrm{MON}^{\mathrm{e}}$} & \multicolumn{2}{|c|}{ Período (PER) } & \multicolumn{3}{|c|}{ Probabilidade } & \multirow{2}{*}{$\mathrm{EPM}^{\mathrm{f}}$} \\
\hline & - & + & - & + & CRES & TER & PAP & MON & PER & \\
\hline $\begin{array}{c}\text { AOL inicial, } \\
\mathrm{cm}^{2}\end{array}$ & 43,66 & 47,39 & 44,78 & 46,27 & $45,52 \mathrm{~b}$ & $61,16 a$ & 0,1205 & 0,5253 & $<, 0001$ & 1,678 \\
\hline $\begin{array}{l}\text { AOL final, } \\
\mathrm{cm}^{2}\end{array}$ & 71,14 & 71,83 & 70,73 & 72,24 & $61,16 \mathrm{~b}$ & $71,48 \mathrm{a}$ & 0,7340 & 0,4635 & $<, 0001$ & 1,470 \\
\hline $\begin{array}{c}\text { GSC inicial, } \\
\mathrm{mm}\end{array}$ & 1,51 & 1,73 & 1,63 & 1,61 & $1,61 \mathrm{~b}$ & $4,08 \mathrm{a}$ & 0,1111 & 0,8610 & $<, 0001$ & 0,120 \\
\hline $\begin{array}{l}\text { GSC final, } \\
\text { mm }\end{array}$ & 5,68 & 5,37 & 5,27 & 5,78 & $4,08 \mathrm{~b}$ & $5,52 \mathrm{a}$ & 0,4278 & 0,1885 & $<, 0001$ & 0,205 \\
\hline $\begin{array}{l}\text { P8 inicial, } \\
\mathrm{mm}\end{array}$ & 2,20 & 2,38 & 2,36 & 2,23 & $2,29 \mathrm{~b}$ & $5,98 \mathrm{a}$ & 0,2940 & 0,4448 & $<, 0001$ & 0,156 \\
\hline $\begin{array}{l}\text { P8 final, } \\
\text { mm }\end{array}$ & 8,52 & 8,08 & 8,29 & 8,32 & $5,98 \mathrm{~b}$ & $8,30 \mathrm{a}$ & 0,3668 & 0,9494 & $<, 0001$ & 0,275 \\
\hline PCQ, kg & 243,28 & 245,39 & $240,20 \mathrm{a}$ & $248,46 b$ & NAg & NA & 0,638 & 0,046 & - & 10,827 \\
\hline $\mathrm{RC}, \%$ & 52,12 & 52,38 & 52,23 & 52,27 & NA & NA & 0,511 & 0,915 & - & 0,953 \\
\hline $\mathrm{GV}, \mathrm{kg}$ & 2,29 & 2,18 & 2,12 & 2,35 & NA & NA & 0,523 & 0,167 & - & 0,393 \\
\hline $\begin{array}{c}\mathrm{GV}, \% \text { do } \\
\text { PCQ }\end{array}$ & 0,93 & 0,89 & 0,88 & 0,94 & NA & NA & 0,522 & 0,392 & - & 0,153 \\
\hline $\begin{array}{l}\text { GAOL, } \\
\mathrm{cm}^{2} / \text { dia }\end{array}$ & 0,252 & 0,224 & 0,238 & 0,238 & 0,236 & 0,240 & 0,2628 & 0,9933 & 0,9427 & 0,020 \\
\hline $\begin{array}{l}\text { GGSC, } \\
\mathrm{mm} / \mathrm{dia}\end{array}$ & 0,038 & 0,033 & 0,033 & 0,038 & 0,037 & 0,033 & 0,1813 & 0,1776 & 0,3919 & 0,002 \\
\hline $\begin{array}{l}\text { GP8, } \\
\mathrm{mm} / \mathrm{dia}\end{array}$ & 0,058 & 0,052 & 0,054 & 0,056 & 0,055 & 0,053 & 0,2051 & 0,7390 & 0,6551 & 0,003 \\
\hline
\end{tabular}

${ }^{\mathrm{ab}} \mathrm{Na}$ mesma linha, médias com letras distintas diferem. ${ }^{\mathrm{c}}$ AOL = área de olho de lombo; GSC = espessura de gordura subcutânea; P8 = espessura da gordura da picanha; PCQ = peso de carcaça quente; $\mathrm{RC}=$ rendimento de carcaça; GV = gordura visceral; GAOL = ganho de AOL; GGSC = ganho de GSC; GP8 = ganho de P8; AOLCARC = AOL final por $100 \mathrm{~kg}$ de peso de carcaça quente. ${ }^{\mathrm{d}} \mathrm{PAP}(-)=$ controle e MON; PAP $(+)=$ PAP e MIX. ${ }^{\mathrm{e}} \mathrm{MON}(-)=$ controle e PAP; MON $(+)=$ MON e MIX.${ }^{\mathrm{f}}$ Erro-padrão da média. ${ }^{\mathrm{g}}$ Não avaliado.

Tabela 4. Perfil de ácidos graxos de bovinos Brangus jovens confinados com anticorpos policlonais (PAP) e/ou monensina sódica (MON)

\begin{tabular}{|c|c|c|c|c|c|c|c|c|}
\hline \multirow{2}{*}{ Ácidos graxos (g/100g) } & \multicolumn{2}{|c|}{ PAP $^{f}$} & \multicolumn{2}{|c|}{$\mathrm{MON}^{\mathrm{g}}$} & \multicolumn{2}{|c|}{ Probabilidade } & \multirow{2}{*}{$\mathrm{EPM}^{\mathrm{h}}$} & \multirow{2}{*}{ Interação } \\
\hline & - & + & - & + & PAP & MON & & \\
\hline C14:0 (mirístico) & 4,322 & 4,388 & 4,540 & 4,170 & 0,7020 & 0,1018 & 0,1257 & $\mathrm{NS}^{\mathrm{i}}$ \\
\hline C16:0 (palmítico) & 27,813 & 28,386 & 28,133 & 28,065 & 0,2131 & 0,8805 & 0,3152 & NS \\
\hline C17:0 (margárico) & 0,965 & 1,018 & 0,987 & 0,995 & 0,3551 & 0,9564 & 0,0395 & NS \\
\hline C18:0 (esteárico) & 14,288 & 13,818 & 14,208 & 13,898 & 0,5853 & 0,7176 & 0,5990 & NS \\
\hline C18:1 (oleico) & 42,116 & 41,525 & 41,468 & 42,173 & 0,5568 & 0,5261 & 0,7199 & NS \\
\hline C18:1 trans-11 (vaccênico) & 0,594 & 0,582 & 0,712 & 0,464 & 0,6605 & 0,6757 & 0,2470 & NS \\
\hline C18:2 (linoleico) & 2,233 & 2,258 & 2,259 & 2,232 & 0,8165 & 0,8043 & 0,0773 & $\mathrm{z}$ \\
\hline $\mathrm{C} 18: 2$ cis- 9 trans -11 (CLA) ${ }^{\mathrm{a}}$ & 0,796 & 0,784 & 0,740 & 0,840 & 0,8795 & 0,1808 & 0,0510 & NS \\
\hline C18:3 n3 (ômega 3) & 0,093 & 0,103 & 0,088 & 0,108 & 0,8275 & 0,5934 & 0,0140 & NS \\
\hline C18:3 n6 (ômega 6) & 0,008 & 0,010 & 0,012 & 0,006 & 0,5537 & 0,5378 & 0,0068 & NS \\
\hline $\mathrm{AGS}^{\mathrm{b}}$ & 48,177 & 48,503 & 48,745 & 47,934 & 0,8037 & 0,5381 & 0,9147 & NS \\
\hline $\mathrm{AGI}^{\mathrm{c}}$ & 50,437 & 50,242 & 49,977 & 50,702 & 0,8779 & 0,5693 & 0,8868 & NS \\
\hline $\mathrm{AGMI}^{\mathrm{d}}$ & 48,100 & 47,855 & 47,609 & 48,346 & 0,8393 & 0,5440 & 0,8444 & NS \\
\hline $\mathrm{AGPI}^{\mathrm{e}}$ & 2,337 & 2,387 & 2,368 & 2,356 & 0,6578 & 0,9202 & 0,0770 & $\mathrm{z}$ \\
\hline AGMI / AGS & 1,004 & 0,997 & 0,986 & 1,016 & 0,8816 & 0,5571 & 0,0353 & NS \\
\hline AGPI / AGS & 0,049 & 0,049 & 0,049 & 0,049 & 0,7611 & 0,9320 & 0,0023 & $\mathrm{z}$ \\
\hline AGPI / AGMI & 0,049 & 0,050 & 0,050 & 0,049 & 0,5480 & 0,6925 & 0,0014 & $\mathrm{z}$ \\
\hline
\end{tabular}

${ }^{\mathrm{a}} \mathrm{CLA}=$ ácido linoleico conjugado; ${ }^{\mathrm{b}}$ AGS $=$ ácidos graxos saturados; ${ }^{\mathrm{c}}$ AGI $=$ ácidos graxos insaturados; ${ }^{\mathrm{d}} \mathrm{AGMI}=$ ácidos graxos monoinsaturados; ${ }^{\mathrm{e}} \mathrm{AGPI}=$ ácidos graxos poli-insaturados; ${ }^{\mathrm{f}} \mathrm{PAP}(-)=$ controle e MON; PAP $(+)=$ PAP e MIX. ${ }^{g}$ MON $(-)=$ controle e PAP; MON $(+)=$ MON e MIX. ${ }^{h}$ Erro-padrão da média. ${ }^{i}$ Não significativo. ${ }^{\mathrm{z}}$ Interação entre PAP e monensina. 


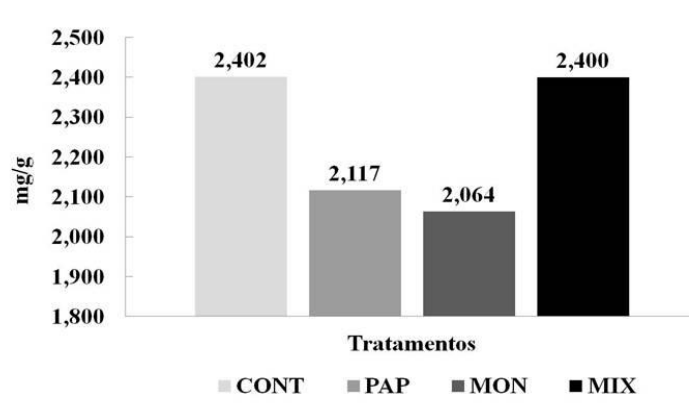

Figura 1. Interação entre PAP e MON para o ácido linoleico da gordura subcutânea de bovinos Brangus jovens confinados.

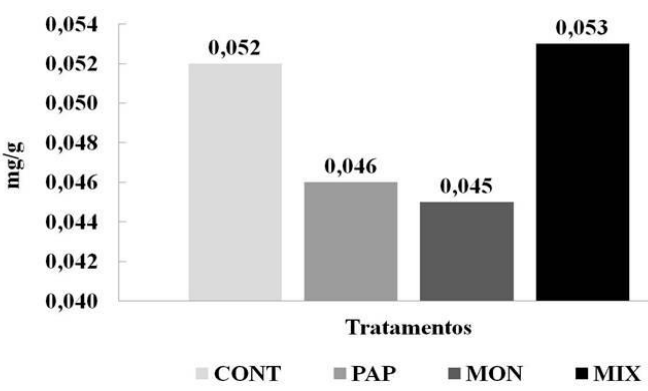

Figura 3. Interação entre PAP e $\mathrm{NON}$ para o AGPI/AGS da gordura subcutânea de bovinos Brangus jovens confinados.

Não foi observado efeito $(\mathrm{P}>0,05)$ principal dos aditivos alimentares sobre as concentrações de lipoproteínas sanguíneas (CLS). Entretanto, nos

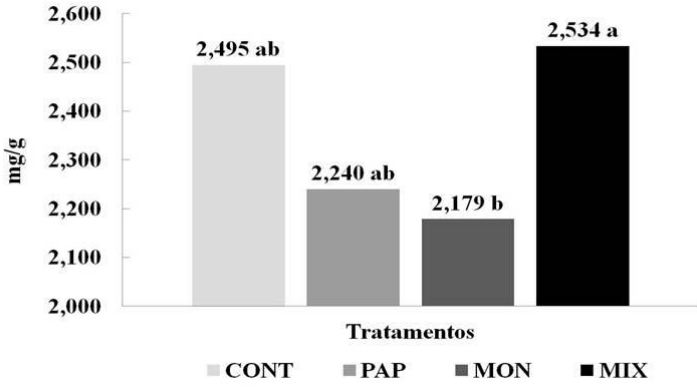

Figura 2. Interação entre PAP e NON para o AGPI da gordura subcutânea de bovinos Brangus jovens confinados. ${ }^{\mathrm{a}, \mathrm{b}}$ Médias na horizontal com diferentes sobrescritos diferem $(\mathrm{P}<0,05)$.

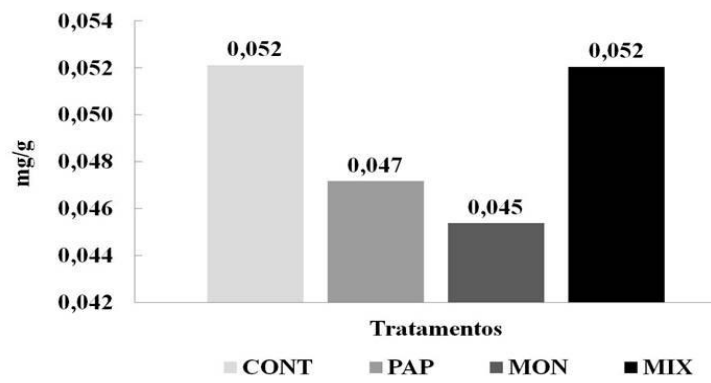

Figura 4. Interação entre PAP e NON para o AGPI/AGMI da gordura subcutânea de bovinos Brangus jovens confinados.

períodos analisados, foi observada diferença $(\mathrm{P}<0,05)$ na CLS (Tab. 5).

Tabela 5. Concentração de lipoproteínas sanguíneas de bovinos Brangus jovens confinados com anticorpos policlonais (PAP) e/ou monensina sódica (MON).

\begin{tabular}{|c|c|c|c|c|c|c|c|c|c|c|c|}
\hline \multirow{2}{*}{ Item } & \multicolumn{2}{|c|}{ PAP $^{g}$} & \multicolumn{2}{|c|}{$\mathrm{MON}^{\mathrm{h}}$} & \multicolumn{3}{|c|}{ Período (PER) } & \multirow[b]{2}{*}{$\mathrm{EPM}^{\mathrm{i}}$} & \multicolumn{3}{|c|}{ Probabilidade } \\
\hline & + & - & + & - & ADAP & CRES & TER & & PAP & MON & PER \\
\hline Colesterol & 105,05 & 98,43 & 104,09 & 99,39 & $68,97 b$ & $124,24 \mathrm{a}$ & $112,02 \mathrm{a}$ & 4,15 & 0,27 & 0,43 & $<.0001$ \\
\hline $\mathrm{HDL}^{\mathrm{c}}$ & 64,28 & 61,01 & 63,6 & 61,68 & $37,13 b$ & $76,22 \mathrm{a}$ & $74,59 a$ & 2,14 & 0,29 & 0,53 & $<.0001$ \\
\hline $\mathrm{LDL}^{\mathrm{d}}$ & 38,69 & 35,8 & 40,92 & 33,57 & $27,55 b$ & $52,34 \mathrm{a}$ & $31,85 \mathrm{ab}$ & 3,95 & 0,61 & 0,20 & 0,02 \\
\hline VLDL $^{\mathrm{e}}$ & 10,72 & 11,08 & 10,5 & 11,29 & $4,93 \mathrm{c}$ & $17,99 a$ & $9,77 \mathrm{~b}$ & 0,65 & 0,69 & 0,39 & $<.0001$ \\
\hline $\mathrm{TG}^{\mathrm{f}}$ & 53,59 & 55,39 & 52,51 & 56,47 & $24,67 \mathrm{c}$ & $89,96 \mathrm{a}$ & $48,85 \mathrm{~b}$ & 3,26 & 0,69 & 0,39 & $<.0001$ \\
\hline
\end{tabular}

${ }^{\mathrm{a}, \mathrm{b}} \mathrm{Na}$ mesma linha, médias com letras distintas diferem. ${ }^{\mathrm{c}} \mathrm{HDL}=$ lipoproteínas de alta densidade; ${ }^{\mathrm{d}}$ LDL $=$ lipoproteínas de baixa densidade; ${ }^{\mathrm{e}} \mathrm{VLDL}=$ lipoproteínas de muito baixa densidade $;{ }^{\mathrm{f}} \mathrm{TG}=$ triglicerídeos. ${ }^{\mathrm{g}} \mathrm{PAP}(-)=$ controle e MON; PAP $(+)=$ PAP e MIX. ${ }^{\mathrm{h}}$ MON $(-)=$ controle e PAP; MON $(+)=$ MON e MIX. ${ }^{i}$ Erro-padrão da média.

\section{DISCUSSÃO}

Com relação à $\mathrm{MON}$, a melhor $\mathrm{CA}(5,57$ vs. $5,79)$ apresentada pelos animais que receberam MON levou ao maior GPD $(1,666$ vs. 1,552) e, consequentemente, a maiores PVF (474,86 vs. 459,61) e PCQ (248,46 vs. 240,20). A melhora de $3,9 \%$ na CA e $7,3 \%$ no GPD corrobora os resultados obtidos por Goodrich et al. (1984), nos quais a adição de $\mathrm{MON}$ à dieta aumentou em $1,6 \%$ o GPD e melhorou em $7,5 \%$ a CA. Isto indica que a MON promoveu maior eficiência no uso da energia da dieta. 
O motivo de melhorar o desempenho animal é atribuído principalmente a incrementos na eficiência energética devido a uma modificação na produção ruminal de ácidos graxos de cadeia curta (AGCC) (Potter et al., 1974), com diminuição da proporção molar de acetato e butirato e aumento da proporção molar de propionato, porém a concentração total de AGCC é pouco afetada. Alguns autores, como Fuller e Johnson (1981), observaram diminuição na relação acetato:propionato com a utilização de MON em dietas de alto grão. Como complemento, Hungate (1966) propôs que a fermentação do propionato é mais eficiente energicamente do que a fermentação do acetato. Isso porque o propionato é o único $\mathrm{AGCC}$ que pode ser convertido à glicose, a qual, então, pode ser utilizada como fonte de energia para ruminantes, e esta, por sua vez, pode ser acrescentada sobre o desempenho animal. Raun et al. (1976) relataram que o efeito da MON na melhora da eficiência alimentar pelas mudanças no padrão da fermentação ruminal, em parte, também está relacionado com a diminuição da produção de metano.

Todas essas mudanças ocorridas com a suplementação da MON podem ter contribuído para melhorar a energia disponível da dieta para absorção, como o encontrado por Brown et al. (1974). Portanto, as vantagens em se obter melhor desempenho com o uso de MON estão no efeito desta sobre o metabolismo de energia e sobre a eficiência do uso de energia para mantença e para crescimento.

A respeito da IMSKG e da IMSPV, não foi observado efeito principal dos aditivos. Em geral, é bem documentada na literatura a redução na IMS quando bovinos em confinamento são alimentados com MON (Tedeschi et al., 2003). Uma possível explicação é a relatada por Byers (1980), o qual afirmou que a adição de MON a dietas isoenergéticas levou à maior melhoria da energia líquida para ganho comparada à energia líquida de manutenção da dieta, o que não alterou a IMS. Desta forma, o menor CKPV (R\$ 3,06 vs. R \$ 3,18) apresentado por animais que consumiram MON pode ser explicado pelo maior GPD (1,666 vs. 1,552), já que não foram constatadas diferenças significativas em termos de IMS.
Por outro lado, não foi observado efeito principal dos aditivos para as características da carcaça, com exceção do PCQ. Os animais que consumiram MON obtiveram $(\mathrm{P}<0,05)$ maior PCQ $(248,46$ vs. 240,20), o que pode ser elucidado pelo fato de terem também apresentado $(\mathrm{P}<0,05)$ maior GPD $(1,666$ vs. 1,552).

Esses dados podem indicar que talvez a suplementação com tais aditivos possa ter ajudado na adaptação dos primeiros dias dos bovinos confinados, e, como consequência, esses animais estavam sadios para aproveitarem as fases seguintes que viriam, utilizando ao máximo a curva de crescimento, com um crescente aumento na fase de CRES e, logo em seguida, na fase de TERM, o início de um declínio. Com isso, tanto os animais suplementados com PAP quanto os suplementados com MON chegaram ao fim do experimento com similares RC.

Não ter encontrado efeito para nenhuma das variáveis deste estudo em relação ao PAP talvez possa ser explicado pelo fato de que o PAP era composto por anticorpos que combatem bactérias ligadas à acidose ruminal. Pode ser que pelo ótimo desempenho apresentado pelos animais e pela ausência de lesões no epitélio ruminal em estudo complementar (Sarti et al., 2009), o PAP não tenha encontrado nicho para atuação. É bem documentado na literatura que as bactérias $S$. bovis e Lactobacillus spp. só crescem em $\mathrm{pH}$ mais baixo, em torno de 5,8 (SchwartzkopfGenswein et al., 2003), e, portanto, ambiente ótimo para atuação do PAP. Todavia, mesmo que o fator descrito acima possa ter mascarado o principal efeito desse aditivo, a inclusão do PAP na dieta não trouxe nenhum efeito negativo.

Para o perfil de ácidos graxos só foi observado efeito entre os tratamentos testados para a variável AGPI (Fig. 2), não sendo observado efeito dos tratamentos PAP, MON e MIX em relação ao CONT. Isso mostra que, provavelmente, o acréscimo dos aditivos alimentares não resultou em mudança na biohidrogenação ruminal. Porém, foi observado efeito entre o tratamento MON e o tratamento MIX para a variável AGPI, com o tratamento MIX apresentando um maior valor que o tratamento MON (2,534 vs. 2,495.), o que indica que, possivelmente, no tratamento MIX houve um sinergismo para diminuir ainda mais a 
bio-hidrogenação ruminal e aumentar o AGPI, contudo sem afetar a quantidade de CLA (Tab. 4).

Entretanto, para maior compreensão dos resultados, no presente estudo poderia ter sido estudada a significância da atividade da enzima $\Delta^{9}$-dessaturase na síntese de CLA. Isso porque, de acordo com Kazala et al. (1999), a atividade dessa enzima é alta na gordura subcutânea (GSC), sendo que o CLA pode ser sintetizado tanto por via endógena, por meio da ação da enzima $\Delta^{9}$-dessaturase sobre o ácido C18:1 trans-11 (ácido vaccênico), como pelo metabolismo ruminal, no processo de biohidrogenação do C18:2 (ácido linoleico) (Pariza, 2001). Bauman et al. (1999) alegaram que esta parece ser a principal via de síntese do CLA presente na gordura de ruminantes. Outro ponto que poderia ter sido analisado para esclarecer melhor os mecanismos para discussão seria avaliar os pontos de deposição de gordura, pois, segundo Sainz (1997), o crescimento do tecido adiposo ocorre na seguinte sequência cronológica: perirrenal e intermuscular, seguido de subcutâneo e intramuscular. De acordo com Bas e Sauvant (2001), a concentração dos ácidos graxos linoleico (C18:2) e linolênico (C18:3) é maior nos músculos do que na GSC. Além disso, um terceiro ponto que poderia ter sido analisado seria fazer uma quantificação no rúmen, para verificar a taxa de bio-hidrogenação e os produtos finais produzidos. Desta forma, poderia ser melhor inferido o que de fato aconteceu e os mecanismos pelos quais ácidos graxos são depositados na gordura das carcaças de bovinos de corte.

Diante dos resultados obtidos neste estudo, a curva de crescimento dos animais no confinamento comportou-se apresentando crescente aumento durante o período de CRES e, em seguida, iniciou-se o declínio no período de TER, demonstrando que, com o aumento da idade e do peso vivo dos animais, ocorre diminuição na eficiência em ganhar massa muscular, fazendo com que a exigência de energia de mantença aumente e a composição do ganho seja, em maior parte, composta por tecido adiposo, o que reduz o GPD e piora a CA e o CKPV (Owens et al., 1993; Valadares Filho et al., 2006).
Outro fator importante que pode ser inferido é com relação à proximidade da puberdade dos animais, momento este em que a deposição do tecido muscular diminui e aumenta a taxa de deposição do tecido adiposo (gordura subcutânea). É sabido que até a puberdade dos bovinos observa-se maior eficiência na conversão dos alimentos em peso corporal, como refletido no presente estudo, obtido por menor CKPV, sendo constatado pela melhor CA no período de CRES em relação ao de TER (Tab. 2). Em concordância com estes resultados, alguns autores mostraram que animais jovens possuem alta eficiência na conversão de alimento em massa muscular e posteriormente em carne, visto que esses animais estão na fase prépuberdade de autoaceleração (Schoonmaker et al., 2002). Ainda, de acordo com o NRC (National..., 1996), devido às menores exigências energéticas de mantença nesse período (CRES), há maior direcionamento da energia para ganhos, o que colabora, desta forma, para a melhor eficiência animal.

Porém, esse declínio no GPD dos animais no período de TER não significa que eles deixaram de crescer ou de engordar, mas sim que esse processo ocorreu com maior CKPV, sendo necessária maior quantidade de alimento para ganho de peso, o que, consequentemente, causa piora da CA. Isso porque, com o passar do tempo, também se inicia a deposição do tecido adiposo, que necessita de maior aporte de energia em relação ao utilizado na deposição do tecido muscular (Owens et al., 1993).

Ainda, o maior teor de concentrado nas dietas de CRES e TER em relação à de ADAP forneceu maior quantidade de energia, que pode ter sido usada pelos microrganismos ruminais para a produção de AGCC. No rúmen, devido à alta concentração de ácidos produzidos, pode ter ocorrido a diminuição do $\mathrm{pH}$ e pode ter sido alterado o padrão da bio-hidrogenação, assim como encontrado por Fuentes et al. (2009), o que explica o aumento das concentrações de HDL e, consequentemente, de colesterol, quando dietas com maior teor de energia foram fornecidas. Isso fica mais evidente no período de TER, no qual as concentrações de LDL, VLDL e triglicerídeos diminuíram em relação ao período de CRES (Tab. 5), ficando clara a alteração em algum processo fermentativo no rúmen, pois a concentração de HDL manteve-se inalterada no 
período de TER, quando comparado ao período de CRES (Tab. 5). Esses efeitos observados podem estar ligados ao fato de que, segundo Troegeler-Meynadier et al. (2006), em pH inferior a seis, a isomerização e a segunda redução (fases da bio-hidrogenação) são inibidas.

\section{CONCLUSÕES}

A inclusão do PAP na dieta de bovinos Brangus não foi boa alternativa à substituição da MON. Por outro lado, a inclusão do PAP não afetou negativamente os itens estudados.

\section{REFERÊNCIAS}

ALLAIN, C.C.; POON, L.S.; CHAN, C.S.G. et al. Enzymatic determination of total serum colesterol. Clin. Chem., v.120, p.470-475, 1974.

BAS, P.; SAUVANT, D. Variations de la composition des dépôts lipidiques chez les bovins. Am. Soc. Anim. Sci., v.14, p.311-322, 2001.

BAUMAN, D.E.; BAUMGARD, L.H.; CORL, B.A. et al. Biosynthesis of conjugated acid in ruminants. Proc. Am. Soc. Anim. Sci., v.4, p.115, 1999.

BROWN, H.; CARROLL, L.H.; ELLISTON N.G. et al. Field evaluation of monensin for improving feed efficiency in feedlot cattle. Proc. Western Sec. ASAS, v.25, p.300, 1974.

BYERS, F.M. Effects of limestone, monensin, and feed level on corn silage net energy values and composition of growth in cattle. J. Anim Sci., v.53, p.873, 1980 .

CHRISTIE, W.W. Simple produce for rapid transmethy lation of glycerolipids and cholesteryl esters. J. Lip. Resear., v.23, p.1-4, 1982.

FAO. WHO. Expert Committee on Food Additives. Codex alimentarius, 2009. Disponível em: <http://www.who.int/foodsafety/chem/jecfa/ publications/en/index.html>. Acessado em: 15 out. 2009.

FUENTES, M.C.; CALSAMIGLIA, S.; CARDOZO, P.W. et al. effect of $\mathrm{pH}$ and level of concentrate in the diet on the production of biohydrogenation intermediates in a dual-flow continuous culture. J. Dairy Sci., v.92, p.4456-4466, 2009.
FULLER, J.R.; JOHNSON, D.E. Monensin and lasalocid effects on fermentation in vitro. J. Anim Sci., v.53, p.1574, 1981.

GOODRICH, R.D.; GARRET, J.E.; GAST, D.R. et al. Influence of monensin on the performance of cattle. J. Anim Sci., v.58, p.1484-1498, 1984.

GREINER, S.P.; ROUSE, G.H.; WILSON, D.E. et al. The relationship between ultrasound measurements and carcass fat thickness and longissimus muscle area in beef cattle. J. Anim Sci., v.81, p.676-682, 2003.

HARA, A.; RADIN, N.S. Lipid extraction of tissues with a low-toxicity solvent. Anal. Biochem., v.90, p.420-426, 1978.

HUNGATE, R.E. The rumen and its microbes. Department of Bacteriology and Agricultural Experiment Station. New York: Academic Press, 1966. 533p.

KAZALA, E.C.; LOZEMAN, F.J.; MIR, P.S. et al. Relationship of fatty acid composition to intramuscular fat content in beef from crossbred wagyu cattle. J. Anim. Sci., v.77, p.1717-1725, 1999.

MARINO, C.T.; OTERO, W.G.P.; RODRIGUES, H.M. et al. Effects of adding polyclonal antibody preparations on ruminal fermentation patterns and digestibility of cows fed different energy sources. J. Anim Sci., v.89, p.3228-3235, 2011.

MILLEN, D.D.; PACHECO, R.D.L.; ARRIGONI, M.D.B. et al. A snapshot of management practices and nutritional recommendations used by feedlot nutritionists in Brazil. J. Anim Sci., v.87, p.3427-3439, 2009.

NATIONAL Research Council - NRC. NUTRIENT requirement of beef cattle. 7.ed. Washington: National Academy Press, 1996. 242p.

OWENS, F.N.; DUBESKI, P.; HANSON, C.F. Factors that alter the growth and development in ruminants. J. Anim. Sci., v.71, p.31-38, 1993.

PARIZA, M.W.; PARK, Y.; COOK, M.E. The biologically active isomers of conjugated linoleic acid. Progress in Lipid Res., v.40, p.283-298, 2001.

POTTER, E.L.; COOLEY C.O.; RICHARDSON, L.F. et al. Effect of monensin upon composition of carcass gain of cattle. J. Anim. Sci., v.39, p.249, 1974. 
RAUN, A.P.; COOLEY, C.O.; POTTER, E.L. Effect of monensin on feed efficiency of feedlot cattle. J. Anim. Sci., v.43, p.670-677, 1976.

SAINZ, R.D. Physiology and manipulation of fat distribution. In: SOUTHWEST NUTRITION AND MANAGEMENT CONFERENCE, 1997, Phoenix. Proceedings... Phoenix: University of Arizona, 1997. p.1-14.

SARTI, L.M.N.; BARDUCCI, R.S.; MILLEN, D.D. et al. Rumen papillae measurements of feedlot cattle fed monensin or polyclonal antibody preparation against lactate-producing rumen bacteria. J. Anim. Sci., v.87, p.284, 2009.

SCHOONMAKER, J.P.; LOERCH, S.C.; FLUHARTY, F.L. et al. Effect of age at feedlot entry on performance carcass characteristics of bulls and steers. J. Anim. Sci., v.80, p.2247-2254, 2002.

SCHWARTZKOPF-GENSWEIN, K.S.; BEAUCHEMIN, K.A.; GIBB, D.J. et al. Effect of bunk management on feeding behavior, ruminal acidosis and performance of feedlot cattle: A review. J. Anim. Sci., v.81, p.149-158, 2003.
STATISTICAL Analysis Sistem. SAS. SAS user's guide: statistics. 5.ed. Cary, 2003. 846p.

TEDESCHI, L.O.; FOX, D.G.; TYLUTKI, T.P. Potential environmetal benefits of ionophores in ruminantes diets. J. Environ. Qual., v.32, p.1591$1602,2003$.

TROEGELER-MEYNADIER， A.; BRET-BENNIS L.; ENJALBERT, F. Rates and efficiencies of reactions of ruminal biohydrogenation of linoleic acid according to $\mathrm{pH}$ and polyunsaturated fatty acids concentrations. Reprod. Nutr. Dev., v.46, p.713-724, 2006.

VALADARES FILHO, S.C.; AZEVÊDO, J.A.G.; PINA, D.S. et al. Consumo de matéria seca de bovinos nelore e mestiços. In: VALADARES FILHO, S.C.; PAULINO, P.V.R.; MAGALHÃES, K.A. (Ed.). Exigências nutricionais de zebuínos e tabelas de composição de alimentos BR-Corte. Viçosa, MG: Universidade Federal de Viçosa, 2006. 142p. 